Article

\title{
The capability Enhancement of DC-Link Voltage Using ARPI Controller for Single-Stage Grid- Connected PV System
}

\author{
Ayman Alhejji ${ }^{1}$ \\ Department of Electrical and Electronics Engineering Technology, Yanbu Industrial College, Yanbu \\ Industrial City 41912, Saudi Arabia; alhejjia@rcyci.edu.sa
}

\begin{abstract}
The article introduces a new solution approach to grid-connected single-stage three-phase PV inverter whereby a dc-link voltage can successfully achieve the desired performance. As a singlestage, the variable output of perturb and observe maximum power point tracking (P\&O basedMPPT) is fully utilized as dc-link voltage reference in inverter control scheme. As a result, it is challenging for the dc-link voltage to preserve energy balance by tracking its variable dc-link voltage reference under unpredictable environmental changes. To overcome this challenge, an adaptive reference proportional-integral (ARPI) controller, self-tuning, is designed and implemented to compel the dc-link voltage tracking its voltage reference to be equal as closely as possible; hence, the capability of the dc-link under abnormal events substantially guarantees the best energy balance and transient performance enhancement. To verify the validity of the method, simulation results for multiple events scenarios on $250 \mathrm{KW}$ single-stage grid-connected PV systems show the effectiveness of the ARPI controller compared with PI controller.
\end{abstract}

Keywords: ARPI; P\&O-based MPPT, Variable DC-Link; Single-Stage; three-level Three-Phase Inverter; Grid Connection.

\section{Introduction}

Solar energy is one of the renewable energy resources solutions combating global energy crises [1]. Solar energy in a form of photovoltaic (PV) technology has been a growing interest in many applications due to its low maintenance, free of noise and pollution, abundantly accessible in nature, and affordable along with efficiency increase of photovoltaic modules as reported in [2-3,5]. In accordance with the system size [3], PV systems are categorized into small scale, intermediate scale, and large scale. Both small and intermediate scales PV systems are exploited to supply electrical energy locally, whereas the large scale or utility scale PV systems deliver electrical energy to the distributed network or auxiliary services.

With increasing demand of electricity, the grid integration of PV energy sources in distribution system has become prevalent called- PV based-distributed generation. Therefore, a gridconnected PV system of the three-phase inverter can be modeled in term of installations such as multistring, centralized and centralized with different MPPT controllers as addressed in [2]. Multistring topology was particularly implemented for utility-scale PV system along with two-level control for direct current boost interface [3]. However, when it comes to ample energy production, the generation of the various renewable energy sources such as solar, wind and hydro is highly penetrating to seasonal weather variations [4]. In [5], the study was dedicated to accomplishing better transient and steady state performance through dc-link voltage controller based adaptive network based fuzzy inference system.

The more PV systems are utilized and integrated with grid, the less environmental pollution exist; however, in the fact that using the PV systems is probably going to impact on power quality, 
safe and stable operation of delivered power. Therefore, it is increasingly significant to find out possible solutions for the issues of reactive power, accurate power flow and power quality in PV systems [6]. In [7], a great effort has been dedicated to investigating ample solutions through various reactive current controls. Similarly, an interesting solution approach to the issue of power quality has been addressed by [8]. Furthermore, the study in [9] was explicitly focused more on adaptive control of reactive power through coordination to enhance the power quality in distribution system along with large scale of PV systems.

Different advanced MPPT control techniques [10-19] have been proposed aiming at simply extracting the maximum energy production from the specified capacity in renewable energy conversion [10]. The aim of this article is not associated with reviewing the effectiveness of MPPT techniques; however, these techniques of MPPT control such as perturb and observe (P\&O)[11-12], incremental conductance (IC)[13][12], parasitic capacitance[14], constant voltage [15] are commonly applied to obtain maximum power point in grid-connected PV system. Moreover, artificial intelligence including fuzzy logic and artificial neural networks based MPPT is mostly combined with the previous conventional MPPT methods in the literature in order to accurately improve the tracking speed [16]. MPPT based on genetic algorithms to deal with nonlinear objective functions [17], fuzzy logic (FC)-based MPPT controller [18] and artificial neural networks (ANN) based MPPT controller [19]. As pointed out in [20], a variable step length of the MPP using incremental conductance was revealed in order to increase the PV power efficiency and stability in single-stage inverter.

For dc-link voltage regulation in single-stage grid connected PV inverter, power loss is rather less, and hence efficiency is better due to single-stage DC-AC power conversion. The control of three-phase three-level PV inverter is designed and implemented by controlling dc-link voltage so that it can sustain the best balance between generated PV power and the utility or distributed networks. Moreover, it controls injected grid current to the grid to cope with generated power quality. A few references have discussed dc-link voltage control in single-stage and stability, so it merits further explorations. For example, as pointed out [21], a single-stage topology has promoted the power produced under partial shading status by enhancing MPPT capability. The enhancement of the dc-link voltage control along with reactive power compensation using feedback linearization technique for single-stage PV system was represented in [22]. Likewise, in [23], an active power decoupling control of single-stage single-phase dual-bulk inverter designed aims at directly controlling the dc-link voltage. Thus, it turns out that the dc-link voltage is equal to the PV voltage in single-stage inverter. In [24], the stability of the dc-link voltage in single-stage PV system connected to weak grid was analyzed. It is worth noting that the more generated PV power supplies, the more negative impact on dc-link voltage happens, and hence reduces the stability margin of the inverter.

Using a proportional-integral (PI) controller in voltage control scheme is simple and advantageous for voltage stability, but from its drawbacks, its mainly depends upon trial and error design, or long computation process in optimization as an off-line tuning [25]-[28], and therein lay the cause of its ineffectiveness comparing with adaptive controller.

Most of the previous studies have not taken into account capability of adaptive voltage controller. Thus, in this framework, the study presents an adaptive reference proportional integral (ARPI) voltage control in a new way which is designed and implemented as online tuning for the dclink voltage stability. However, a key limitation of this operation is that when a maximum power point (MPP) produces a new voltage reference, this voltage reference is essentially limited by different levels of solar irradiance and temperature. Because of that limitation, the dc-link voltage becomes variable afterward. Therefore, it is a challenge to regulate dc-link voltage to track the new voltage reference.

Key contributions to single-stage three-phase grid-connected PV system are dedicated to enhance variable dc-link voltage stability. As a dc-link voltage is generally responsible for holding the best power balance, a proper controller is needed to improve stability of grid-connected PV inverter whereby it is enhancing the dc-link voltage performance. To that, an adaptive reference integral-proportional (ARPI), online, is designed and examined in voltage control scheme. This devised ARPI aims at regulating the dc-link voltage by tracking the dc-link voltage reference 
developed from MPPT. The performance enhancement is further investigated through several tests. These tests such as immense variations of solar irradiance and temperature, short-circuit fault, and voltage dip are ample to distinguish performance capability of dc-link voltage-based ARPI controller compared with PI controller.

\section{System Description}

Consider a single-stage three-phase grid-connected PV system shown in Figure 1. As a singlestage three-level inverter, the inverter control unit greatly comprises of MPPT control, voltage control and current control, phase locked loop (PLL) synchronization, and pulse width modulation (PWM) generator.

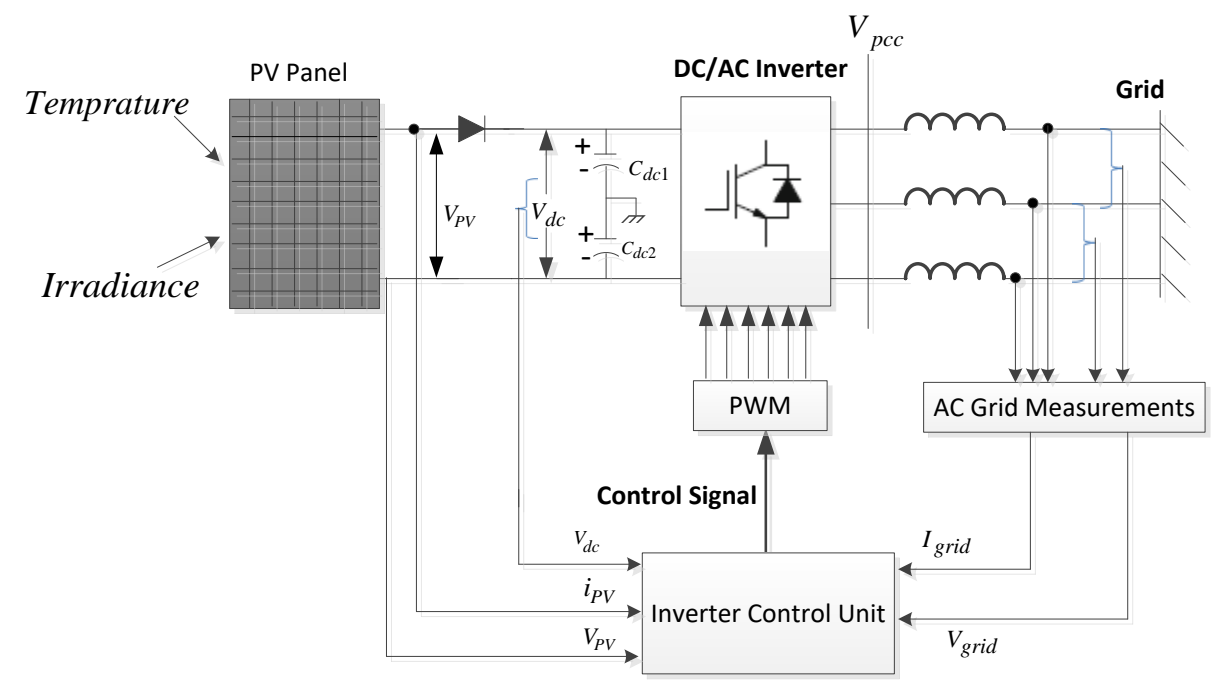

Figure1. Feature of the single-stage grid-connected PV system.

\subsection{Photovoltaic Module.}

As described in Figure 2, $I_{P V}$ expresses the photovoltaic current based on solar irradiance and temperature conditions; $I_{d}$ represents the current passing through diode, and $I_{p}$ denotes the current passing through parallel resistor, and $V_{P V}$ denotes the voltage terminal output of PV module. $R_{s}$ and $R_{P}$ describe the series and parallel resistances, respectively.

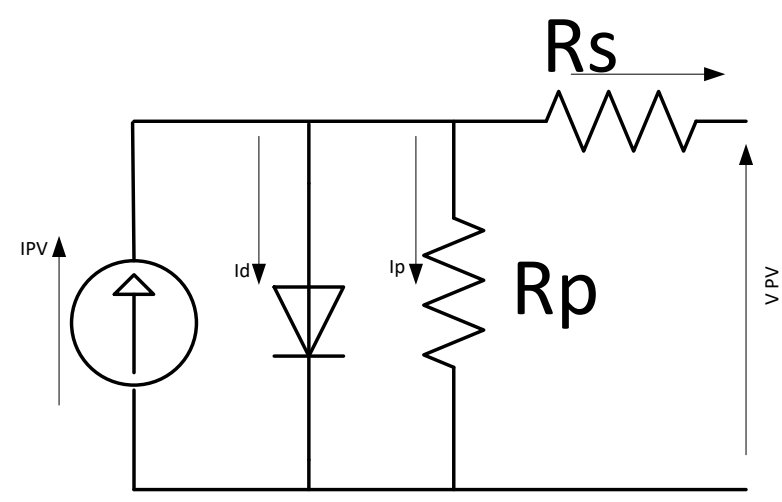

Figure 2. Equivlent circuit of the PV module. 
According to extensive study in [29], the P\&O based MPPT implemented in single-stage microinverter guarantees 0.98 power factor of the system, $4.7 \%$ total current distortion (THD), and $93 \%$ efficiency of the inverter.

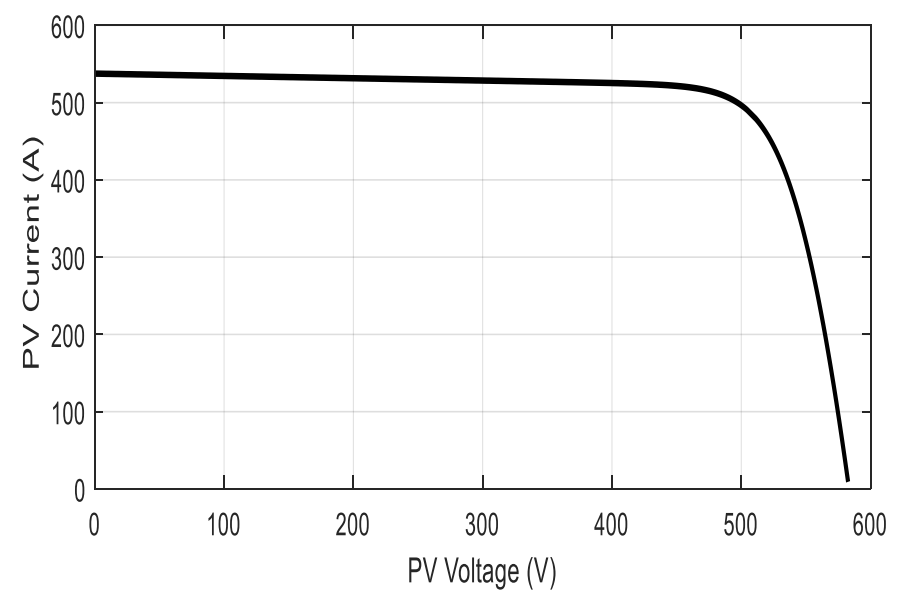

(a)

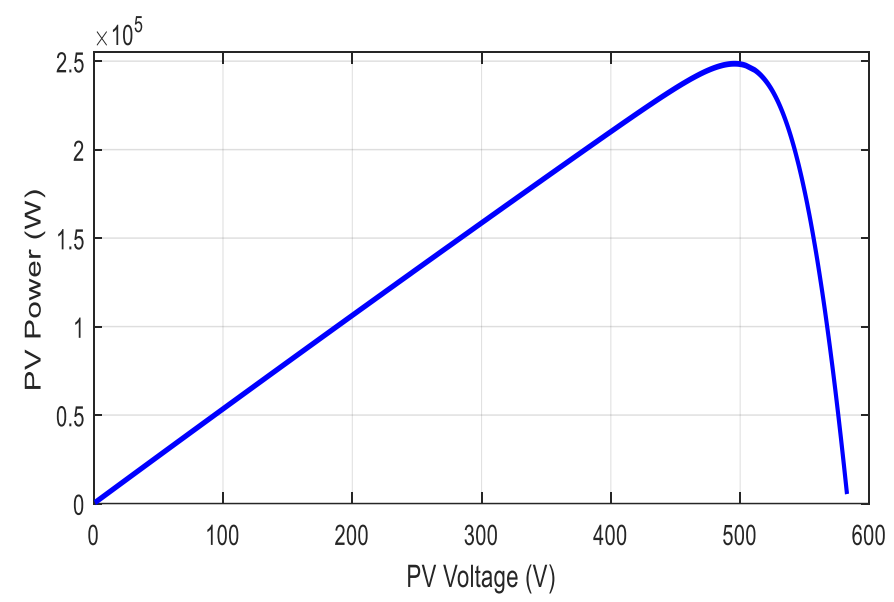

(b)

Figure 3 :(a) I-V characteristics, and (b) P-V characteristics of the output PV panel.

\subsection{Adaptive Single-Stage Inverter}

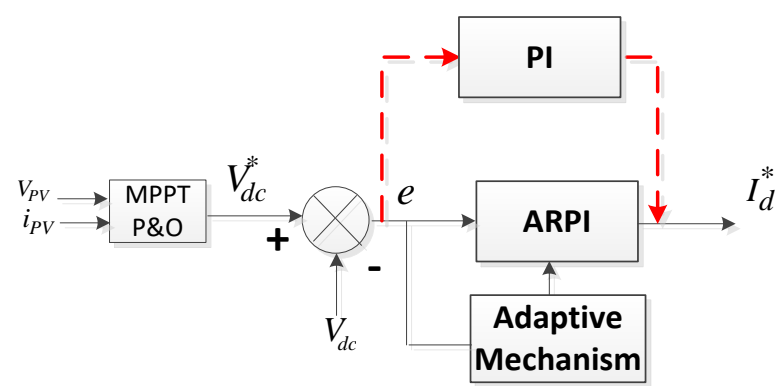

(a)

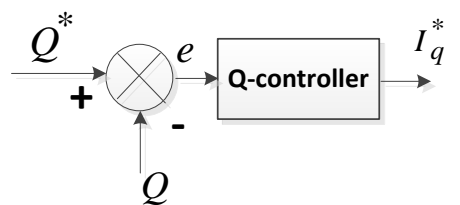

(b) 


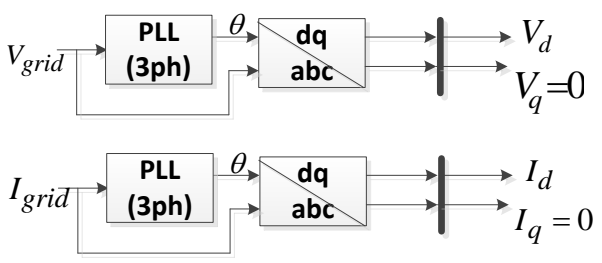

(c)

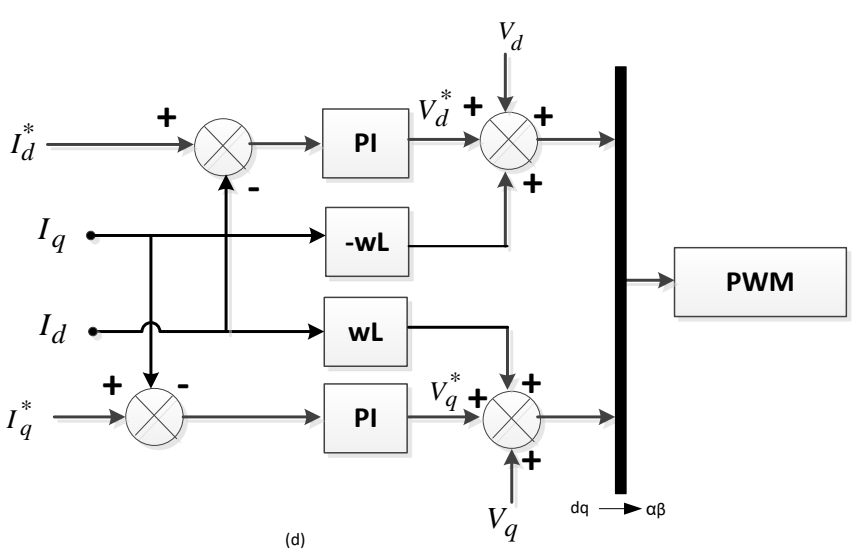

Figure 4. Adaptive single-stage inverter scheme. A) outer controller which its output is reference for active current control ;b) Q-controller which its output is set to be zero ; c) d-and q-axis components of the grid voltage and current; d) grid model

As a PV panel is directly connected to dc-link capacitor in single-stage three-phase inverter, the duty cycle of $\mathrm{P} \& \mathrm{O}$ based-MPPT output is feed-forward as the dc-link reference voltage $v_{d c}^{*}$ for the dc-link voltage scheme. In the system configuration seen in Figure 1, a dc-dc converter is not comprised. Consequently, the three-phase inverter control unit relies heavily on such as $\mathrm{P} \& \mathrm{O}$ basedMPPT output, feedback dc-link voltage measurement, and feedbacks of the grid voltage and current to regulate the three-phase switching of the inverter. Single-stage three-phase PV inverter is explicitly shown in Figure 1. A variable step is improved in P\&O based-MPPT controller whereby it adopts different step length values by increasing or decreasing voltage and eventually determines new dclink voltage reference $v_{d c}^{*}$. It is meritorious that a devised ARPI is capable for online tuning parameters so fast in voltage control scheme, and promises good performance in the event of faults. The key role of the ARPI controller is to compel the dc-link voltage to track its new reference as closely as possible. Consequently, the best balance between generated PV power and grid is efficiently maintained with better transient performance.

\section{Proposed DC-link Voltage Control.}

Numerous control techniques such as [5],[9]-[10] and [21]-[24] have been proposed and implemented to regulate the dc-link voltage. Owing to abnormal conditions such environmental changes and voltage dip events in PV system, solutions of the control problems have increasingly been enhanced, especially for dc-link voltage control in order to maintain a power balance between generation and grid. Through control of direct current axis, the dc-link voltage control in single-stage inverter can be successfully achieved and the injection of real power can be controlled accordingly. However, the pragmatic control scheme in the framework first exploits the error (between variable dc-link reference voltage and measured dc-link voltage) for adaptation of the control parameters of adaptive reference integral-proportional (ARPI) controller.

$$
\frac{1}{2} C \frac{d V_{d c}^{2}}{d t}=P_{p v}-P_{\text {grid }}
$$

For simplicity $P_{p v}=i_{p v} \times v_{p v}$ and $P_{\text {grid }}=1.5 \times v_{d} i_{d}$, the dc-link voltage dynamics becomes

$$
C \frac{d V_{d c}}{d t}=i_{p v}-1.5 \frac{v_{d}}{v_{d c}} i_{d}
$$

where $P_{p v}, i_{p v}, v_{p v}$ are the output PV power in watt, output PV current in Amp, and output PV voltage in volt, respectively. Moreover, $i_{d}$ is a direct current axis in Ampere to control the active power to the grid. $v_{d}$ describes the direct voltage axis in volt. $V_{d c}$ denotes a dc-link voltage in volt aimed at maintaining the best balance between generation and grid. 


\section{Simulation Results and Discussion.}

To verify the validity of the proposed control approach, consider 250KW single-stage threephase PV system given in Figure 1 which was simulated using MATLAB/SIMULINK. Various case simulation scenarios, applied to the given system, aim at testing the enhancement and capability of the dc-link voltage using ARPI controller, and hence they are compared with PI controller. PI control parameters are obtained as outlined in table 1.

The results, including three simulation scenarios are implemented and discussed below.

- Scenario1: the effect of environmental changes.

- Scenario2: the effect of environmental changes along with short-circuit fault simultaneously.

- Scenario3: the effect of environmental changes along with voltage dip simultaneously.

Table 1. Parameters of proportional-integral (PI) control.

\begin{tabular}{cc}
\hline $\begin{array}{c}\text { PI Control } \\
\text { parameters }\end{array}$ & Values \\
\hline $\mathrm{KP}$ & 2 \\
$\mathrm{KI}$ & 400 \\
\hline
\end{tabular}

\subsection{Scenario 1: The effect of environmental changes.}

Consider weather changes on PV panel which mainly affects on output PV power afterward.Thus, capability assessemt of overall PV plant is required under such effects, particularly for power balance through controlled dc-link to accomplish the best match between output PV power and demand power.

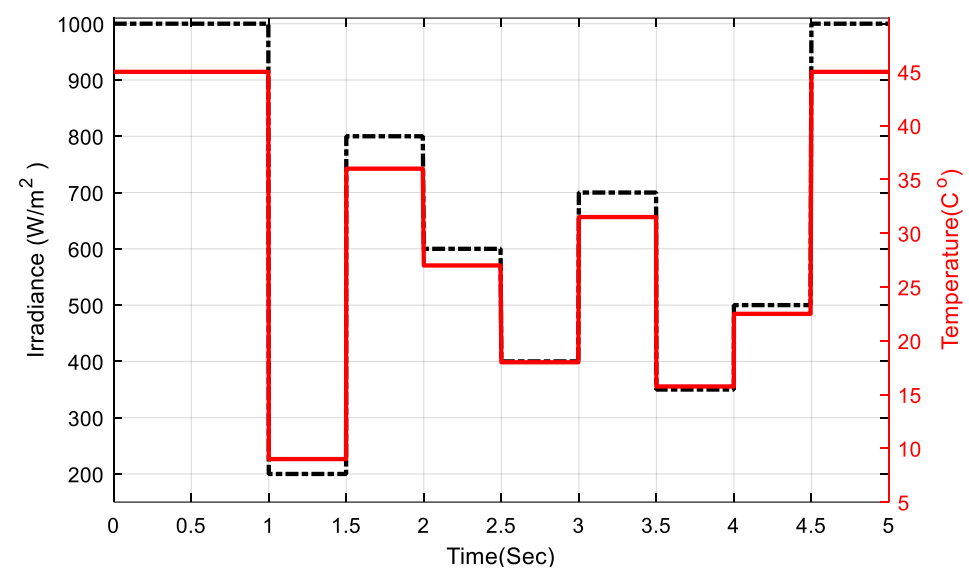

Figure5. Environmental conditions of Solar Irradiance and Temperature.

Figure 5 clearly shows the variations of solar irradiance and temperature over time. The MPPT has been obtained through these measurements of continuous variations. The result of the output power from PV has been fluctuated because of irradinace and temperature in Figure 6a. Likewise, as depicted in Figure $6 \mathrm{~b}$, the performance result of the dc-link voltage-based PI controller seems to be sluggish to follow dc-link voltage reference. On the other hands, the significance of the ARPI's finding is that the dc-link voltage based-ARPI controller guarantees faster and smoother transient performance over random variations of solar irradiance and temperature. Furthermore, dc-link voltage based-ARPI is to converge to its dc-link voltage reference with less overshoot in multiple variations. It is important to point out that the key reseaon behind the variable dc-link existance as seen in Figure $6 \mathrm{~b}$ mainly attributes to the variations of irradiance levels. In Figure $6 \mathrm{c}-\mathrm{d}$, it has been found that the voltage at point of common coupling (PCC) and grid power have been affected by continuous weather variations on PV panel. 


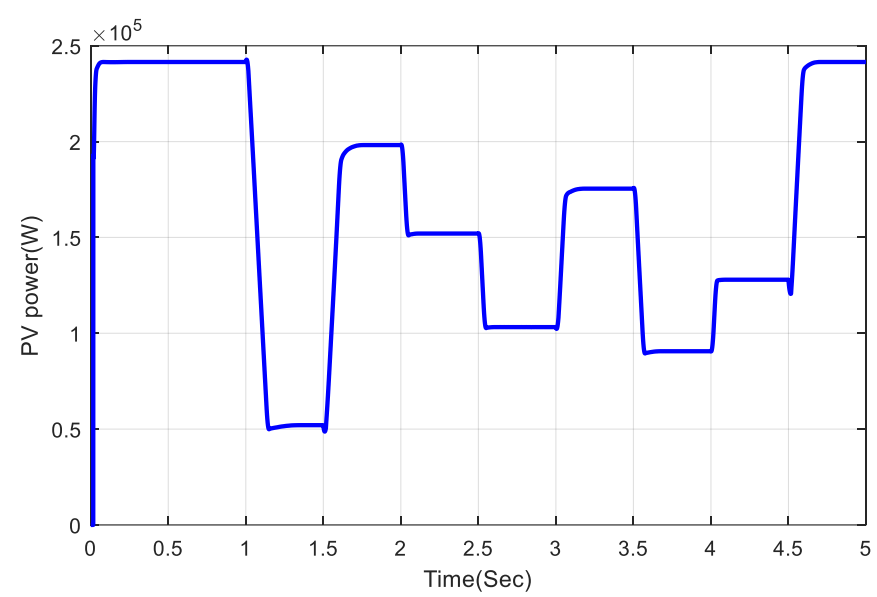

(a)

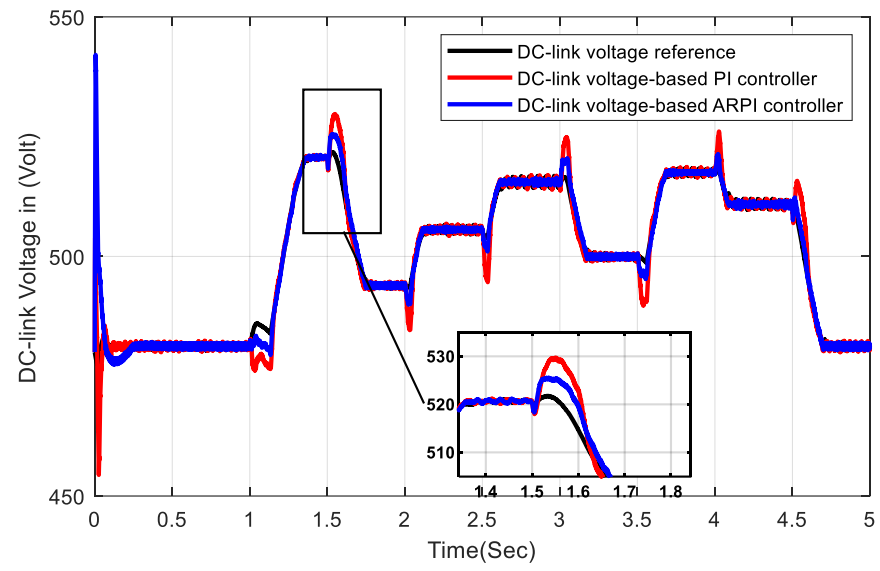

(b)

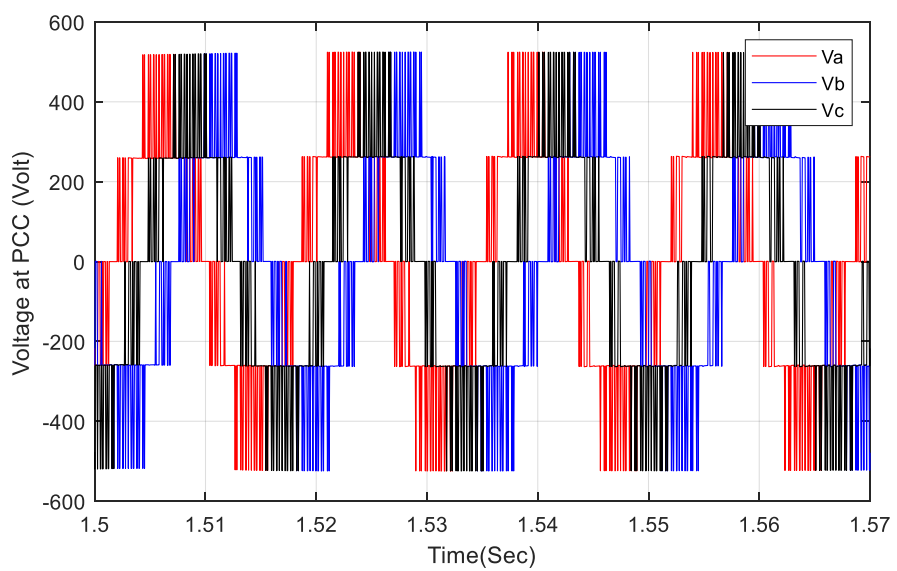

(c) 


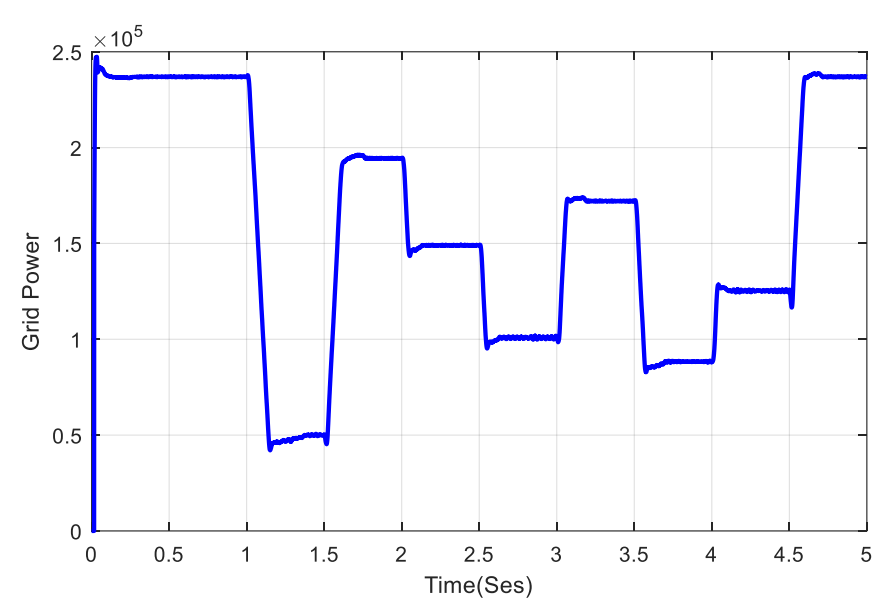

(d)

Figure 6. Performance results over random solar irradiance and temperature. (a) Output PV power .(b) DC-link voltage performance, (c) Voltage at PCC in per unit and (d) enhanced grid power.

4.2. Scenario 2: The effect of environmental changes along with short-circuit faults.

The capability assessment of ARPI controller implemented in voltage control scheme is tested by three-phase short-circuit fault at point of common coupling while continous weather change as seen in Figure 5 is occurring.

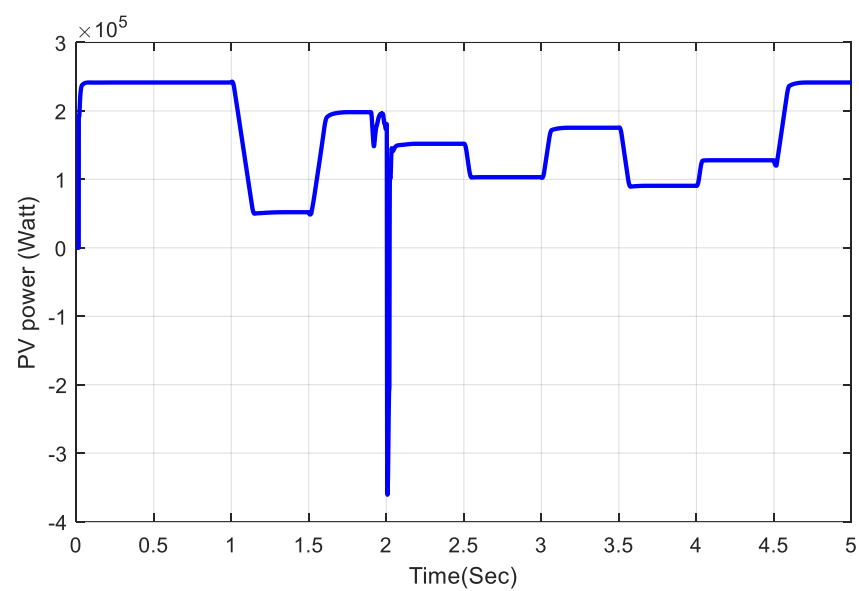

(a)

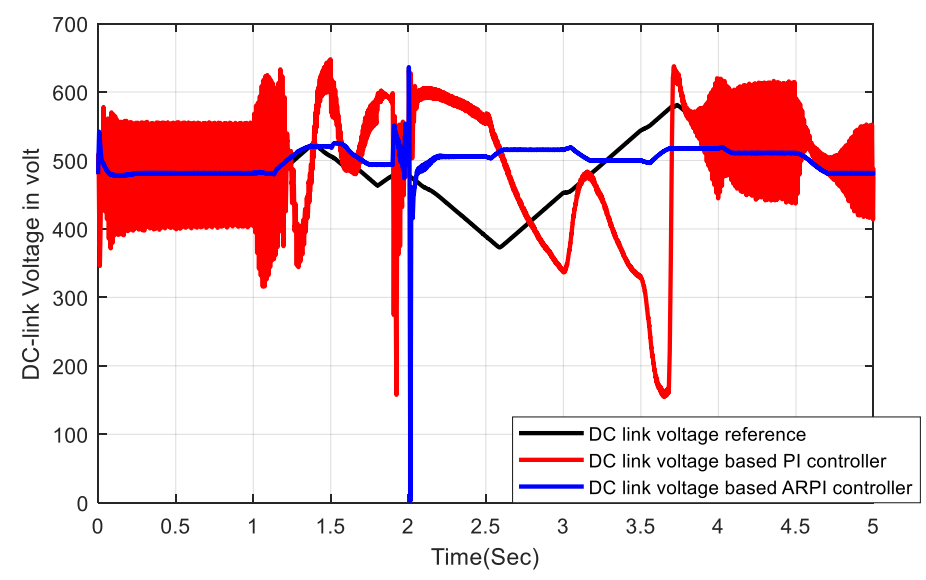


(b)

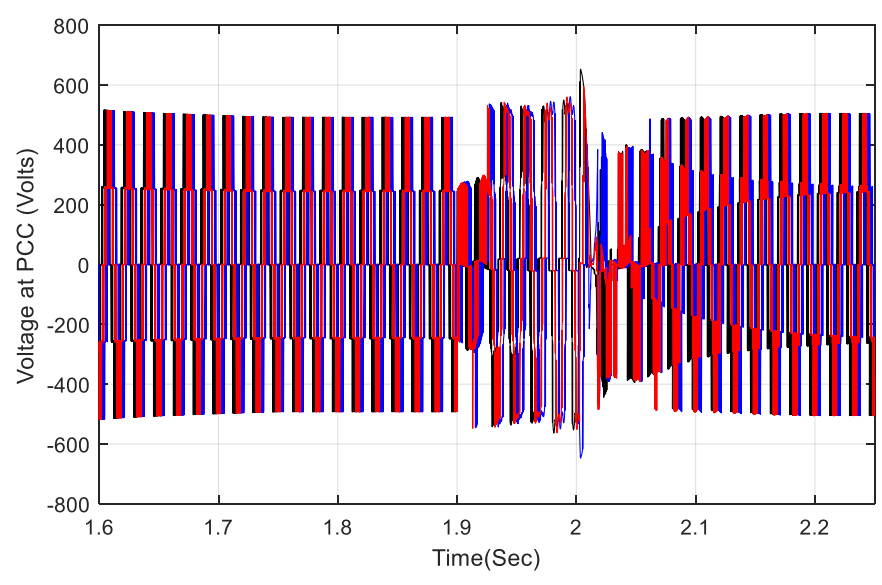

(c)

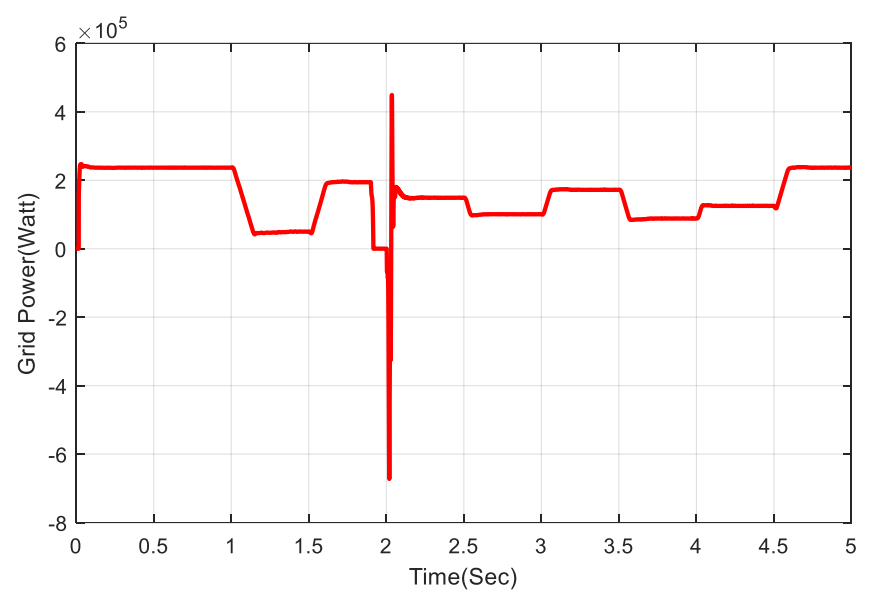

(d)

Figure 7. Performance results of three-phase short-circuit test over environmental changes. (a) Output PV power .(b) DC-link voltage performance, (c) Voltage at PCC, and (d) Enhanced grid power.

Simulation results in Figure 7 illustrate the effects of simultaneous weather changes and shortcircuit fault placed from $1.9 \mathrm{sec}$ to $2 \mathrm{sec}$. As shown in Figure 7a, owing to weather changes as main inputs to PV panels, it is reflected in the reduction of output PV power continously. In case of singal stage inverter, deriving MPPT out of random output voltage and current to generate a new voltage reference causes the variable dc-link voltage reference. As can be seen from Figure $7 \mathrm{~b}$, the dc-link voltage-based PI controller is not as effective as the dc-link voltage-based ARPI controller. As depicted, the dc-link voltage using ARPI controller is explicitly less affected by the short-circuit fault placed from $1.9 \mathrm{sec}$ to $2 \mathrm{sec}$, and is rapidly tracking the variable dc-link voltage reference $V_{d c}^{*}$ to uphold the best balance between generated PV power and grid power during continuous weather changes. Such case is also depicted in Figure 7c-d, voltage at pcc and grid power having capability to overcome the applied three-phase short-circuit fault from $1.9 \mathrm{sec}$ to $2 \mathrm{sec}$ can presume to its continuous weather changes as expected.

\subsection{Scenario 2: The effect of enviromental changes along with voltage dip.}

Note that causes of the voltage dip in grid-connected PV system can be nonlinear load variations, large load connections. As a result of that, voltage dip leads to oscilating output voltage and output distorting current in grid side. 


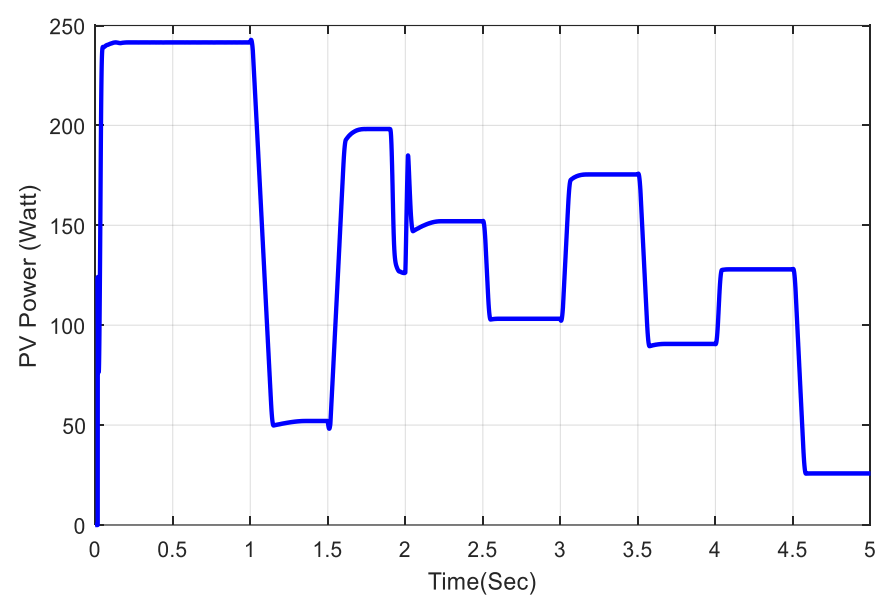

(a)

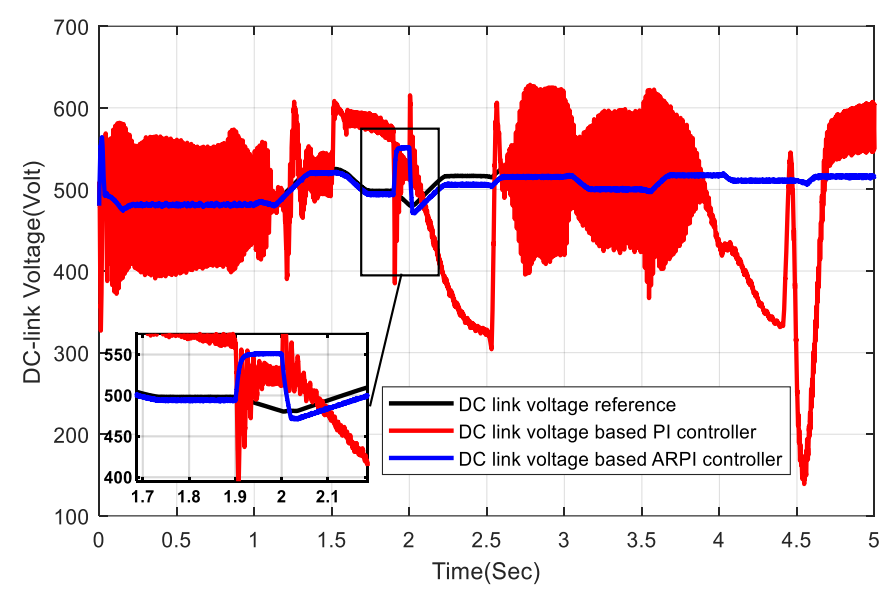

(b)

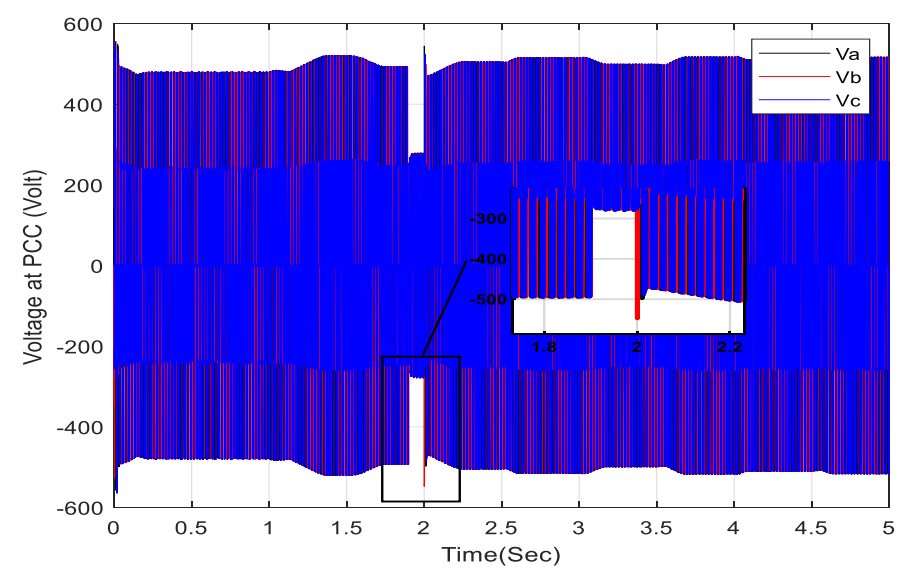

(c) 


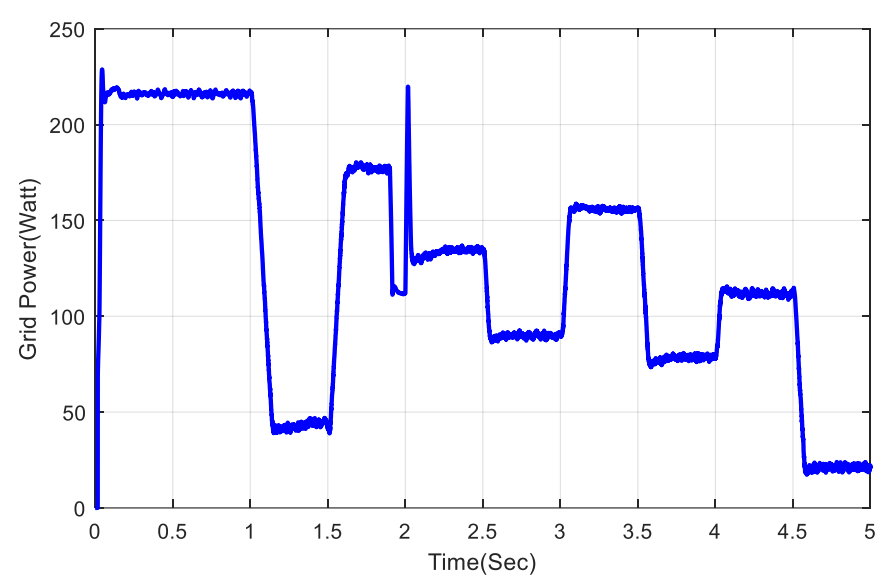

(d)

Figure 8. Performance results of environmental changes with voltage dip, (a) Output PV power, (b) DC-link voltage performance, (c) Voltage at PCC , and (d) Enhanced grid power.

To illustrate the results of the singal stage PV system over environmental change along with voltage dip, the simulation is performed under the effects of weather change and voltage dip as shown in figure 8. In Figure 8a, the PV power output was mainly affacted by atomsphere. Figure 8b shows that unlike dc-link voltage-based PI, the dc-link voltage based ARPI has a fast and smooth convergence to the new voltage reference as closely as possible. It is significant that the tracking error between dc-link voltage reference and its measured dc-link voltage reaches zero to ensure stability of dc-link in order to maintain the best power balance. As described in Figure 8c, the voltage at PCC was explicitly presumed to its effect of continuous weather changes as expected after voltage dip had released. Likewise, the result of the enhanced grid power as seen in Figure $8 \mathrm{~d}$ performs like the output PV power despite of unpredictable events.

\section{Conclusions}

Single-stage PV system has been investigated in multiple case simulation scenarios to examine the capabilities of the ARPI on dc-link voltage control when P\&O-based MPPT generates new dc-link voltage reference. Because of stable online adaptation, the control action of ARPI always performs faster than PI controller. It is therefore desired to point out that the capability enhancement has demonstrated the significant results of ARPI compared with PI controller used in voltage control. Despite abnormal events like environmental changes, short-circuit fault and voltage dip, ARPI has enhanced transient stability performance of the variable dc-link, and the best power balance between output PV power and grid was preserved as expected.

\section{References}

1. B. Singh, S. Kumar and C. Jain. Damped-SOGI-Based Control Algorithm for Solar PV Power Generating System. IEEE Transactions on Industry Applications. 2017, 53, pp.1780-1788.

2. M. M. Hashempour, M. Yang and T. Lee. An Adaptive Control of DPWM for Clamped-Three-Level Photovoltaic Inverters With Unbalanced Neutral-Point Voltage. IEEE Transactions on Industry Applications.2018, 54,pp.6133-6148.

3. P. Wu, W. Huang and N. Tai. Novel grid connection interface for utility-scale PV power plants based on MMC. The Journal of Engineering.2019. 2019,16, 2683-2686.

4. Ll. Lledo, V. Torralba, A. Soret, J. Ramon, F.J. Doblas-Reyes. Seasonal forecasts of wind power generation. Renewable Energy.2019. 143,91-100.

5. Kouro, S., Leon, J., Vinnikov, D., et al. Grid-connected photovoltaic systems: an overview of recent research and emerging PV converter technology. IEEE Ind. Electron. Mag. 2015. 9, (1), 47-61. 
6. Yang, Y., Enjeti, P., Blaabjerg, F., et al.Wide-scale adoption of photovoltaic energy: grid code modifications are explored in the distribution grid. IEEE Ind. Appl. Mag. 2015. 21, (5), 21-31.

7. Hernández, J.C., Bueno, P.G., Sanchez-Sutil, F. Enhanced utility-scale photovoltaic units with frequency support functions and dynamic grid support for transmission systems. IET Renew. Power Gener. 2017. 11, (3), 361-372.

8. Fu, X., Chen, H., Cai, R., et al. Optimal allocation and adaptive VAR control of PV-DG in distribution networks. Applied Energy. 2015. 137,173-182

9. X. Fu, Q. Fu and W. Tang. Grid connection technique based on $\mu$ theory for a two-stage PV structure. IET Power Electronics. 2019. 12.6. 1545-1553.

10. C. Jain and B. Singh. A Three-Phase Grid Tied SPV System With Adaptive DC Link Voltage for CPI Voltage Variations. IEEE Transactions on Sustainable Energy.2016. 7, 1, 337-344.

11. L. Piegari, R. Rizzo, Adaptive perturb and observe algorithm for photovoltaic maximum power point tracking, IET Renew. Power Gener. 4 (4) (2010) 317-328.

12. D. Sera, L. Mathe, T. Kerekes, S. V. Spataru and R. Teodorescu. On the Perturb-and-Observe and Incremental Conductance MPPT Methods for PV Systems. IEEE Journal of Photovoltaics. 2013. vol. 3, no. 3, pp. 1070-1078.

13. A. Brambilla, M. Gambarara, A. Garutti, F. Ronchi, New approach to photovoltaic arrays maximum power point tracking. 30th Annual IEEE Power Electronics Specialists Conf.1999, PESC 99, vol. 2, pp. 632-637.

14. D.P. Hohm, M.E. Ropp, Comparative study of maximum power point tracking algorithm using an experimental programmable, maximum power point tracking test bed. Proceedings 28th IEEE Photovoltaic Specialist Conf., 2000, pp. 1699-1702.

15. W. Swiegers, J. Enslin, An integrated maximum power point tracker for photovoltaic panels, in: Proceedings IEEE International Symposium on Industrial Electronics, vol. 1, 1998, pp. 40-44.

16. S. Lyden, M.E.Haque. Maximum Power Point Tracking techniques for photovoltaic systems: A comprehensive review and comparative analysis. Renewable and Sustainable Energy Reviews. 2015.52.15041518.

17. Shaiek Y, Smida MB, Sakly A, Mimouni MF. Comparison between conventional methods and GA approach for maximum power point tracking of shaded solar PV generators. Solar Energy. 2013, 90,107-22

18. Alajmi BN, Ahmed KH, Finney SJ. Williams BW. Fuzzy-logic-control approach of a modified hill-climbing method for maximum power point in microgrid standalone photovoltaic system. IEEE Trans Power Electron. 2011;26(4),1022-1030.

19. Santi Agatino Rizzo and Giacomo Scelba. ANN based MPPT method for rapidly variable shading conditions. Applied Energy. 2015, 145,124-132.

20. W. Libo, Z. Zhengming and L. Jianzheng, "A Single-Stage Three-Phase Grid-Connected Photovoltaic System With Modified MPPT Method and Reactive Power Compensation. 2007. IEEE Transactions on Energy Conversion, vol. 22, no. 4, pp. 881-886.

21. H. Ghoddami; A. Yazdani. A Single-Stage Three-Phase Photovoltaic System With Enhanced Maximum Power Point Tracking Capability and Increased Power Rating. 2011. IEEE Transactions on Power Delivery, 26, 2, 1017-1029.

22. Vivek Nandan Lal; S. N. Singh. Control and Performance Analysis of a Single-Stage Utility-Scale GridConnected PV System. 2017. IEEE System Journal. 11.3.1601-1611.

23. Duck-Hwan Hwang; Jung-Yong Lee; Younghoon Cho. Single-phase single-stage dual-buck photovoltaic inverter with active power decoupling strategy. Renewable energy. 2018. 126.454-464.

24. Gangui Yan, Jun Ren, Gang Mu, Liguang Jin, Shuangming Duan and Qi Jia. DC-link voltage stability analysis for single-stage photovoltaic VSIs connected to weak grid.2016. IEEE 8th International Power Electronics and Motion Control Conference (IPEMC-ECCE Asia). 474-478.

25. Feng Gao, Ding Li, P. C. Loh, Yi Tang and Peng Wang, "Indirect dc-link voltage control of two-stage singlephase PV inverter," IEEE Energy Conversion Congress and Exposition, San Jose, CA.2009. 1166-1172.

26. M. S. El Moursi, W. Xiao and J. L. Kirtley, "Fault ride through capability for grid interfacing large scale PV power plants," in IET Generation, Transmission \& Distribution.2013. 7, 9,1027-1036.

27. R. N. Tripathi and T. Hanamoto, "FRIT based optimized PI tuning for DC link voltage control of grid connected solar PV system," IECON 2015 - 41st Annual Conference of the IEEE Industrial Electronics Society, Yokohama, 2015, pp. 001567-001572.

28. P. Mishra, A. K. Pradhan and P. Bajpai, "Voltage control of PV inverter connected to unbalanced distribution system," in IET Renewable Power Generation.2019. 13, 9, 1587-1594. 
29. PetreusD, Daraban S, Ciocan I, Patarau T, Morel C, Machmoum M. Low cost single-stage micro-inverter with MPPT for grid connected applications. Solar Energy.2013.92,241-255. 